\title{
MENGENALI PATOGENESIS DAN PENYEBARAN SKABIES DI DAERAH BERIKLIM TROPIS DAN SUBTROPIS
}

\author{
Vanneetha Arivananthan \\ ${ }^{1}$ Program Studi Pendidikan Dokter, Fakultas Kedokteran Universitas Udayana \\ (dr.vanneetha@gmail.com)
}

\begin{abstract}
ABSTRAK
Pendahuluan: Skabies telah menyebar ke seluruh dunia, terutama pada daerah beriklim tropis dan subtropis. Skabies merupakan penyakit kulit yang masih sering dijumpai di Indonesia. Penyakit ini mudah sekali menular dan banyak faktor yang membantu penyebarannya.Di Indonesia insiden penyakit ini belum ada angka yang pasti, namun berdasarkan laporan Departemen Kesehatan, skabies menempati urutan ke-3 dari 10 urutan penyakit kulit terbesar pada pelita IV. Cara penularan yaitu melalui kontak langsung (kontak kulit dengan kulit) dan dapat juga secara tidak langsung (melalui benda). Gejala yang dirasakan penderita adalah rasa gatal terutama pada malam hari (pruritus nocturnal) atau saat cuaca panas serta saat pasien berkeringat.

Kasus: Pasien laki-laki, umur 11 tahun, suku Bali, beragama Hindu datang pada 22 April 2014 dengan keluhan timbul bintik-bintik pada sela-sela jari tangan, punggung tangan, telapak tangan, perut bagian bawah dan pada bagian kulit batang penis yang terasa gatal terutama pada malam hari. Keluhan ini sudah dirasakan sejak \pm 1 bulan yang lalu. Penderita dikatakan tidak memiliki riwayat alergi terhadap makanan dan obat.
\end{abstract}

Kata Kunci : gatal, menular, skabies.

\section{ABSTRACT}

Introduction: scabies has spread throughout the world, especially in the tropics and subtropical. Scabies is a skin disease are often found in indonesia. This disease it was easy contagious and a lot of factors help their spreading. In Indonesia, incident this disease is not a definite number, but based on health department report, scabies ranked 3rd than 10 of the largest the skin diseases in Pelita IV. Transmission through direct contact (skin contact) and may also indirectly (through things). Patient symptoms is the itchy feeling especially at night (pruritus nocturnal) or during hot weather and when patients sweating.

Cases: Patients men, age 11, Balinese ethnic, religious Hindu come on april 22nd 2014 with complaints spots show up on the sidelines of the fingers, the back of the hand, palms, lower abdominal and that part of the penis that feels itchy especially at night. This symptoms have been felt since 1 month ago. There is no food and drug allergic history in patient and family.

Keyword: itchy, contagious, scabies.

\section{PENDAHULUAN}

Skabies merupakan penyakit kulit yang masih sering dijumpai di Indonesia. Penyakit ini mudah sekali menular dan banyak faktor yang membantu penyebarannya antara lain: kemiskinan, higiene individu yang jelek, lingkungan yang tidak sehat, berkembangnya prostitusi dan derajat sensitisasi individu.

Di beberapa negara berkembang prevalensinya dilaporkan berkisar antara 6-27\% dari populasi umum dan insiden tertinggi terdapat pada anak usia sekolah dan remaja. ${ }^{1}$ Di negara maju, termasuk Amerika Serikat, prevalensinya sama untuk semua kelompok usia dan skabies pada anak-anak tetap merupakan suatu masalah besar. Di Indonesia insiden penyakit ini belum ada angka yang pasti, namun berdasarkan laporan Departemen Kesehatan, skabies menempati urutan ke-3 dari 10 urutan penyakit kulit terbesar pada pelita IV, Budiastuti dkk pada tahun 1990-1992 melaporkan bahwa penyakit skabies merupakan pengunjung kedua terbesar dari kunjungan rawat jalan poliklinik Rumah Sakit Dr.Sutomo Surabaya. ${ }^{2}$

Penyakit skabies merupakan great imitator of all skin disease artinya keluhan dan gejalanya menyerupai banyak penyakit kulit lain. ${ }^{3,4}$ Keadaan ini 
mengakibatkan pengobatan menjadi tidak tepat, sehingga perluasan dan penyebaran penyakit pun bertambah berat, yang pada akhirnya biaya pengobatan pun menjadi semakin mahal.

Karena penyakit ini menimbulkan rasa sangat gatal (terutama pada malam hari), maka tentu saja dapat mengurangi produktivitas kerja dan bagi anakanak di sekolah akan sangat mengganggu proses belajar oleh sebab itu sangat penting bagi dokter umum untuk mengetahui lebih lanjut lagi mengenai penyakit ini sehingga pada akhirnya dapat memberikan pengobatan yang tepat sehingga komplikasi yang diakibatkan oleh penyakit ini dapat dicegah dan kualitas hidup dapat ditingkatkan.

Penyakit skabies disebut juga gudik,budukan,gatal agogo. ${ }^{4} \mathrm{Di}$ beberapa negara sinonim penyakit ini adalah the itch (Inggris) ${ }^{1,2,3,4}$, mite infestation $^{1}$, kartze (Jerman) ${ }^{1}$, gale (Prancis) ${ }^{1}$. Penyakit ini disebabkan oleh infestasi dan sensitisasi terhadap Sarcoptes scabiei var. hominis dengan ditandai oleh papul dan vesikel pada daerah predileksi dengan rasa gatal pada malam hari. ${ }^{4,5}$

Skabies telah menyebar ke seluruh dunia, terutama pada daerah beriklim tropis dan subtropis. ${ }^{6} \mathrm{Di}$ Indonesia insiden penyakit ini belum ada angka yang pasti, namun berdasarkan laporan Departemen Kesehatan, skabies menempati urutan ke-3 dari 10 urutan penyakit kulit terbesar pada pelita IV, Budiastuti dkk pada tahun 1990-1992 melaporkan bahwa penyakit skabies merupakan pengunjung kedua terbesar dari kunjungan rawat jalan poliklinik Rumah Sakit Dr.Sutomo

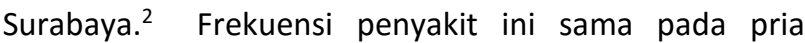
maupun wanita. ${ }^{3,7}$

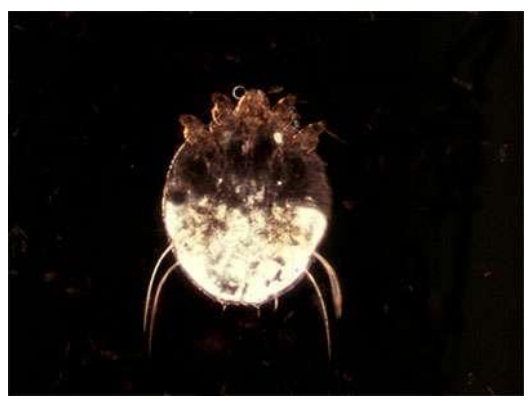

Gambar 1 Sarcoptes scabei

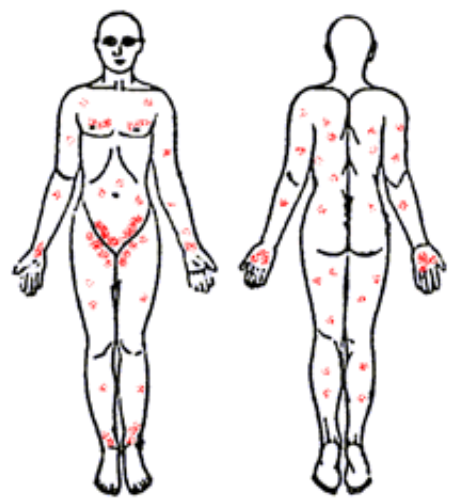

Gambar 2 Tempat predileksi skabies

Cara penularan yaitu melalui kontak langsung (kontak kulit dengan kulit) misalnya berjabat tangan, tidur bersama dan hubungan seksual. Penularan juga dapat secara tidak langsung (melalui benda) misalnya pakaian, handuk, seprei, bantal,dan lain-lain. Penularannya biasanya oleh Sarcoptes scabiei betina yang sudah dibuahi atau kadang-kadang oleh bentuk larva. Dikenal pula Sarcoptes scabiei var,animalis yang kadang-kadang dapat menulari manusia, terutama pada mereka yang banyak memelihara binatang peliharaan misalnya anjing. ${ }^{1,2,4,6,8}$

Tungau jantan dan betina berkopulasi pada terowongan yang dangkal pada kulit, $^{9}$ setelah melakukan kopulasi S.scabei jantan akan mati, kadangkadang masih dapat hidup beberapa hari dalam terowongan yang digali oleh yang betina. Tungau betina yang telah dibuahi menggali terowongan dalam stratum korneum, dengan kecepatan 2-3 milimeter sehari terutama pada malam hari dan sambil meletakkan telurnya 2 atau 4 butir sehari. Telur akan menetas, biasanya dalam waktu 3-5 hari dan menjadi larva yang setelah 2-3 hari akan menjadi nimfa. Terowongan pada kulit dapat sampai ke perbatasan stratum korneum dan stratum granulosum. ${ }^{10}$ Seluruh siklus hidupnya mulai dari telur sampai bentuk dewasa memerlukan waktu antara 8-12 hari. ${ }^{2,4,5,6,8}$

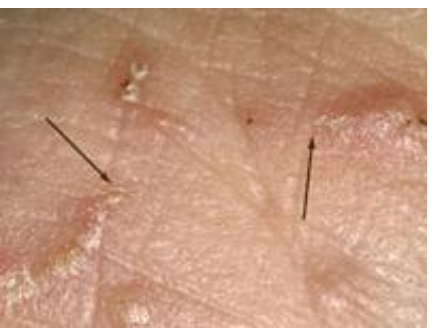

Gambar3 Terowongan (ditunjukkan tanda panah)

Keluhan utama yang dirasakan penderita adalah rasa gatal terutama pada malam hari (pruritus 
nocturnal) atau bila cuaca panas serta pasien berkeringat, ${ }^{1,4,11,12}$ oleh karena meningkatnya aktivitas tungau saat suhu tubuh yang meningkat. ${ }^{1,13}$ Rasa gatal disertai gejala lainnya, biasanya timbul 3-4 minggu setelah tersensitisasi oleh produk tungau dibawah kulit. ${ }^{1,4}$

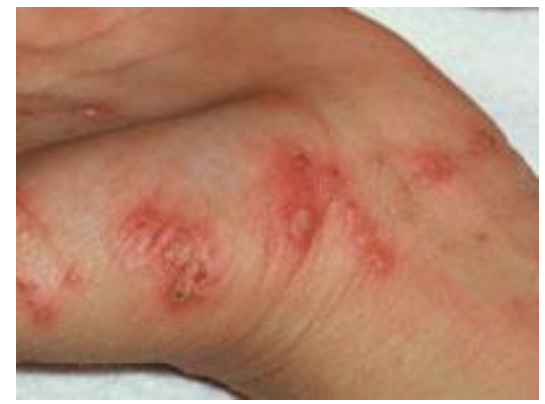

Gambar 4 Pustul pada tangan

Sarcoptes scabei varian canisadalah scabies ditularkan melalui hewan yang dapat menyerang manusia dengan pekerjaannya berhubungan erat dengan hewan tersebut. Misalnya peternak dan gembala. Gejalanya ringan, rasa gatal kurang, tidak timbul terowongan, lesi terutama terdapat pada tempat-tempat kontak. Skabies jenis ini tidak menimbulkan masalah serius pada manusia karena tungau ini bersifat relatif host spesifik, infestasinya biasanya bersifat self limiting, $^{12}$ masa tunas lebih pendek. ${ }^{14}$ Dan dapat sembuh sendiri bila menjauhi hewan tersebut dan mandi yang bersih. 7,14,15

\section{KASUS}

Pasien laki-laki, umur 11 tahun, suku Bali, beragama Hindu datang pada 22 April 2014 dengan keluhan timbul bintik-bintik pada sela-sela jari tangan, punggung tangan, telapak tangan, perut bagian bawah dan pada bagian kulit batang penis yang terasa gatal terutama pada malam hari. Keluhan ini sudah dirasakan sejak \pm 1 bulan yang lalu. Penderita dikatakan ibunya tidak memiliki riwayat alergi terhadap makanan dan obat.

Dari riwayat dikatakan ayah penderita terkena penyakit yang sama seperti penderita dikarenakan penderita saat tidur masih ditemani oleh ayah penderita. Salah satu saudara penderita juga mulai mengalami gejala yang sama.

Sejak keluhan dirasakan, ayah penderita telah memberikan bedak caladin pada daerah lesi tetapi tidak ada perbaikan
Penderita dikatakan ayahnya tidak mempunyai sakit apa-apa sebelum bintik tersebut muncul.

Pada status fisik saat datang dan status generalis ditemukan dalam batas normal.

Dari status dermatologi pada lokasi : sela-sela jari tangan, punggung tangan, telapak tangan, perut bagian bawah, dan kulit batang penis ditemukan kelainan dengan effloresensi : papul multipel berwarna seperti kulit, bentuk bulat, ukuran $\pm 1-2 \mathrm{~mm}$, tersebar diatas kulit yang normal dan tampak beberapa erosi dan ekskoriasi diantaranya.

Tidak dilakukan pemeriksaan tungau dan pemeriksaan penunjang lain pada penderita. Penderita didiagnosis dengan skabies.

Penderita ditata laksana dengan CTM 3 tablet dalam sehari dan obat topikal Permetrin cream 5\%. Serta dilakukan KIE tentang pemakaian krim dioleskan di permukaan tubuh mulai dari leher ke bawah, setelah 8 12 jam kemudian dibersihkan. Apabila belum sembuh dapat diulangi seminggu kemudian; meningkatkan kebersihan perorangan maupun lingkungan dengan cara mandi teratur dan bersih serta mencuci pakaian dan seprei dengan bersih dan bila perlu direndam dengan air panas; meningkatkan daya tahan tubuh dengan istirahat yang cukup dan makan yang teratur dan gizi berimbang; apabila kulit terasa gatal, diusahakan jangan digaruk agar tidak menimbulkan luka yang lebih luas.

\section{DISKUSI}

Skabies adalah penyakit kulit yang disebabkan oleh infestasi dan sensitisasi terhadap Sarcoptes scabiei var,hominis dengan ditandai oleh papul dan vesikel pada daerah predileksi dengan rasa gatal pada malam hari. ${ }^{4,5}$

Diagnosis penyakit ini ditegakkan melalui hasil anamnesis, gambaran klinis dan juga pemeriksaan penunjang. Dari hasil anamnesis, penderita mengeluhkan timbul bintik-bintik pada sela-sela jari tangan, punggung tangan, telapak tangan, perut bagian bawah, dan kulit batang penis yang terasa gatal terutama pada malam hari. Keluhan ini sudah dirasakan sejak 1 bulan yang lalu. Dari hasil anamnesis yang diperoleh mengarah ke perjalanan penyakit skabies dimana dikeluhkan timbul bintik-bintik dan terasa gatal terutama pada malam hari dan tempat predileksi sesuai dengan tempat predileksi penyakit skabies.

Melalui pemeriksaan fisik pasien didapatkan status dermatologi pada lokasi sela-sela jari tangan, punggung 
tangan, telapak tangan, perut bagian bawah dan kulit batang penis ditemukan kelainan kulit dengan effloresensi papul multipel berwarna seperti kulit, bentuk bulat, ukuran $\pm 1-2 \mathrm{~mm}$, tersebar diatas kulit yang normal dan tampak beberapa erosi dan ekskoriasi diantaranya.

Hasil pemeriksaan fisik yang didapat juga mengarah ke diagnosis penyakit skabies karena ditemukan adanya papul-papul yang terdapat pada daerah sela-sela jari tangan dan kulit batang penis yang merupakan tempat predileksi penyakit skabies.

Diagnosa yang memungkinkan selain skabies adalah prurigo, gigitan serangga dan pedikulosis korporis. Gambaran klinik prurigo ialah adanya papulpapul miliar berbentuk kubah terutama terdapat di ekstremitas bagian ekstensor dan terasa sangat gatal yang dirasakan bisa sepanjang waktu tidak hanya pada malam hari. ${ }^{16}$ Diagnosis prurigo bisa disingkirkan melihat tempat predileksi dan rasa gatal yang tidak sesuai dengan keluhan penderita.

Gambaran klinik gigitan serangga berupa makula eritema yang ditengahnya tampak seperti ada bintik bekas gigitan serangga dan terasa gatal yang dirasakan bisa sepanjang waktu. Predileksinya biasanya pada ekstremitas. Diagnosis gigitan serangga bisa disingkirkan melihat gambaran klinik,tempat predileksi dan rasa gatal yang tidak sesuai dengan keluhan penderita.

Gambaran klinik pedikulosis korporis umumnya hanya ditemaukan kelainan berupa bekas-bekas garukan pada badan, karena gatal baru berkurang dengan garukan yang lebih intensif. Penyakit ini biasanya menyerang orang dewasa terutama pada orang yang jarang mandi atau jarang mengganti dan mencuci pakaian. Lebih sering ditemukan pada daerah beriklim dingin karena orang memakai baju yang tebal serta jarang dicuci. ${ }^{17}$ Diagnosis pedikulosis dapat disingkirkan melihat gambaran klinik serta faktor predisposisi yang tidak sesuai dengan keluhan penderita.

Diagnosis pasti penyakit skabies dapat ditegakkan bila menemukan tungau Sarcoptes scabei melalui kerokan, insisi maupun biopsi pada lesi. Pemeriksaan ini tidak dilakukan tetapi diagnosis skabies bisa ditegakkan apabila menemukan 2 dari 4 tanda kardinal. ${ }^{4}$ Pada pasien ini dikeluhkan timbulnya bintikbintik pada sela-sela jari tangan dan kulit batang penis yang terasa gatal terutama pada malam hari serta ada keluarga di rumah yang terkena hal yang sama. Dari anamnesis dan pemeriksaan fisik ditemukan adanya 3 dari 4 tanda kardinal untuk penyakit skabies yaitu rasa gatal pada malam hari (pruritus nokturnal) dan timbulnya papul-papul pada daerah sela-sela jari tangan dan kulit batang penis serta di keluarga pasien lebih dari 1 orang yang menderita. Untuk itu pada kasus ini diagnosa kerjanya adalah skabies. Pada penderita diberikan pengobatan topikal dan sistemik. Pada terapi sistemik diberikan anti histamin yaitu CTM untuk mendapatkan efek anti pruritusnya. Pada terapi lokal diberikan krim permetrin 5\% yang fungsinya sebagai skabisid. Dipilih permetrin krim karena sifat skabisidnya sangat baik, aman karena efek toksisitasnya sangat rendah, dan kemungkinan keracunan karena salah penggunaan sangat kecil. Hal ini disebabkan karena hanya sedikit obat yang diabsorbsi dan obat dimetabolisme sangat cepat sehingga dapat digunakan untuk semua umur termasuk bayi dan anak-anak ${ }^{1}$

Selain terapi obat, KIE juga sangat penting untuk kesembuhan pasien karena penyakit ini dapat disebabkan higiene yang kurang baik. KIE yang diberikan kepada pasien ini yaitu Meningkatkan kebersihan perorangan maupun lingkungan dengan cara mandi teratur dan bersih serta mencuci pakaian dan seprei dengan bersih dan bila perlu direndam dengan air panas, meningkatkan daya tahan tubuh dengan istirahat yang cukup dan makan yang teratur dan gizi berimbang, apabila kulit terasa gatal, diusahakan jangan digaruk agar tidak menimbulkan luka yang lebih luas serta diberitahukan cara pemakaian krim yaitu dioleskan di permukaan tubuh mulai dari leher ke bawah, setelah 812 jam kemudian dibersihkan. Apabila belum sembuh dapat diulangi seminggu kemudian dan kontrol kembali bila obat telah habis. Prognosis penyakit ini baik bila semua hal tersebut dilaksanakan dengan baik.

\section{DAFTAR PUSTAKA}

1. Ayerbe FJ, Munoz JB. Ivermectin for crusted Norwegian scabies induced by use of topical steroids. Arch Dermatol 1998;134:143-5

2. Sudirman T, Skabies : Masalah Diagnosis dan Pengobatannya, dalam Majalah Kedokteran Damianus, Volume 5, Fakultas Kedokteran Universitas Katolik Indonesia Atma Jaya, Jakarta,2006, p 177-190 
3. Siregar RS. Penyakit kulit karena parasit dan insekta, Atlas Berwarna Saripati Penyakit Kulit, Edisi Kedua, Penerbit Buku Kedokteran EGC, 2004, p 164-5

4. Handoko RP. Skabies dalam Ilmu Penyakit Kulit dan Kelamin. ed. Djuanda A; Edisi Keempat, Fakultas Kedokteran Universitas Indonesia, Jakarta, 2005, p 122-5

5. Gandahusada Srisari, Illahude Herry, Pribadi wita. Skabies, dalam Parasitologi Kedokteran, Edisi Ketiga, Fakultas Kedokteran Universitas Indonesia, Jakarta, 2003,p 264-6

6. Fitzpatric TB, Johnson RA, Wolff K, Suurmond D. Scabies. Color Atlas and Synopsis of Clinical Dermatology : Common and Serious Disease, 2nd edition New York : Mc Graw-Hill Book Co, 2001 : 834-843

7. Harahap M. Skabies dalam Ilmu Penyakit Kulit. ed. Harahap M; Hipokrates 1998, p 109-113

8. Jerome Goddard, Scabies Mites (Human Itch or Mange Mites) in Arthropods of Medical Importance, 4th edition Mississippi : CRC Press, 2000: $241-5$

9. Prendiville JS. Scabies \& Lice in Harper J, Oranje A, Prose N (eds). Textbook of Pediatric Dermatology. Blackwell Science. 2000. 555-62

10. Soedarto M. Skabies dalam Daili SF, Makes WIB, Zubier F, dkk (ed). Penyakit menular seksual. Edisi kedua. FKUI Jakarta. 2003 : 162-8

11. Derbes VJ. Arthropod bites and stings in Fitzpatric $T B$, Eisen AZ, Wolff K, Freedberg IM, Austen KF (eds). Dermatology in General Medicine 2nd ed New York : Mc Graw-Hill Book Co, 1979: 1659-60

12. Burns DA. Disease caused by arthropods and other noxious animals. Dalam : Champion $\mathrm{RH}$, Burton JL, Ebling FGJ, editor. Rook/Wilkinson/Ebling Textbook of Dermatology, edisi ke-5. London : Blackwell Science, 1992.h. 1300-07

13. Pardo RJ, Kerdel FA. Scabies. Paracites, arthropods and hazardous animals of dermatologic significance. Dalam : Moschella SL, Hurley HJ, Flecher J, dkk. Editor. Dermatology, edisi ke-3. Philadelphia : WB Saunders Co. 1992.h.1960-67
14. Makatutu MA. Penyakit kulit oleh parasit dan insekta. Dalam Harahap M (ed). Penyakit Kulit. Jakarta. PT.Gramedia. 1990 : 100-104

15. Handoko RP. Infestasi parasit pada kulit anak daalm Daili SF, Bramono K, Dwihastuti P, Nugrohowati T. (ed) Pendekatan diagnosis dan penatalaksanaan penyakit kulit dan kelamin pada anak. Edisi pertama, FKUI Jakarta, 1989 : 28-32

16. Wiryadi BE. Prurigo dalam Ilmu Penyakit Kulit dan Kelamin. ed. Djuanda A; Edisi Keempat, Fakultas Kedokteran Universitas Indonesia, Jakarta, 2005, p 272-275

17. Handoko RP. Pedikulosis Korporis dalam Ilmu Penyakit Kulit dan Kelamin. ed. Djuanda A; Edisi Keempat, Fakultas Kedokteran Universitas Indonesia, Jakarta, 2005, p 120-122. 